\title{
Investigation of Fundamental Mechanism of Crushing of Clods in a Rod Mill
}

\author{
Masayuki Oishi' ${ }^{1}$ Yoshihiro Kubota2 ${ }^{2 *}$, Osamu Mochizuki3 \\ ${ }^{1}$ Daiki Rika Kogyo Co., Ltd., Kōnosu, Japan \\ ${ }^{2}$ Department of Mechanical Engineering, Toyo University, Tokyo, Japan \\ ${ }^{3}$ Department of Biomedical Engineering, Toyo University, Tokyo, Japan \\ Email: *kubota548@toyo.jp
}

How to cite this paper: Oishi, M., Kubota Y. and Mochizuki, O. (2019) Investigation of Fundamental Mechanism of Crushing of Clods in a Rod Mill. Engineering, 11, 703-716.

https://doi.org/10.4236/eng.2019.1110045

Received: September 18, 2019

Accepted: October 7, 2019

Published: October 10, 2019

Copyright (c) 2019 by author(s) and Scientific Research Publishing Inc. This work is licensed under the Creative Commons Attribution International License (CC BY 4.0).

http://creativecommons.org/licenses/by/4.0/

(c) (i) Open Access

\begin{abstract}
A new planetary-type rod-mill machine that we developed for use at a research institute improves the working efficiency of comminution. It also prevents the generation of soil dust, and the jar is easy to keep clean. This device breaks up clods into soil of a small particle size $(<2-\mathrm{mm}$ diam.) within two minutes. The performance of our device is sufficiently satisfactory compared with other conventional machines. However, the exact crushing mechanism remains unclear. We sought to answer questions such as what kinds of strains cause the crushing of clods in the rotating jar, whether or not the maximum strength exceeds the yield stress of the soil, and what is the function of rods during quick crushing. An objective of this study was to understand fundamental mechanisms of crushing clods to further improve the milling device. We carried out compression and shear stress tests using a vibrating container and shearing device to observe the crushing mechanism due to a single stress acting on a clod. We used a charged-coupled device digital camera to visually capture the crushing event in these tests. We found the centrifugal forces produced by rotation of our machine's jar to be much smaller than the critical forces of the amorphous yield point of the clods. The crushing occurs actually in a short time if two rods are in the jar. Soil dust observed in the early stage of the crushing process is produced because the surface of a soil clod is worn initially by shearing forces caused by the rods. After the surface of a clod is scraped, it fragments into small particles catastrophically. The shearing forces exerted by the rods are more effective than the compressive forces in comminution by our rod-mill machine. These results suggest that the cause of crushing clod is the sharing forces acting on the clod for the initial stage.
\end{abstract}

\section{Keywords}

Milling, Fragmenting, Crushing, Soil, Planetary Gear, Visualization 


\section{Introduction}

Several ways to comminute a soil have been devised: using pestles, mortars, and sieves, by hand; using milling machines, with rods, balls, hammer, and air jets applied to soils in a jar; using mechanical crushers, powered by electricity to apply jaws, gyrating rods, rollers, and disc and edge runners. Comminution mechanisms have not been precisely explained for each type of mill machine. Advantages and disadvantages of previous comminution methods were discussed by Powel and Morrison [1]. This kind of review is useful when an existing mill machine is redesigned or modified. However, the previous comminution models were constructed by applying empirical equations (i.e., Kick's, Bond's, and Rittinger's equations), and it is difficult to apply empirical data derived from a specific mill to another type of mill to improve its performance. However, because these equations show the relation between particle size and the energy required to break up the particles, they are convenient for evaluating mill performance. Vogel and Peukert [2] developed an approach to quantify crushing based on using two theoretically derived material parameters and dimensional analysis while also considering mechanical fracturing. One of these parameters is the resistance of particulate material to fracturing in impact comminution, and the other parameter is specific energy. They combined the two parameters to form a dimensionless variable to be applied to the complete breakage function for any material. Therefore, particle size, impact energy, and material characteristics are dominant parameters for describing the crushing.

Gay [3] introduced a liberation model for comminution that was derived from probability theory. This probability-entropy model reasonably describes the comminution processing of ore as a relation between parent and progeny particles. Lob-Guerrero and Vallejo [4] analyzed the crushing of granular material under isotropic and biaxial stress conditions and found that the internal friction angle decreased as a result of particle crushing. Tromans [5] considered the theoretical energy efficiency of comminution for improving processing efficiencies and estimated the maximum ideal limiting efficiency from the stress-state model in a single particle containing a central crack.

Liu [6] investigated breakage and deformation mechanisms experimentally by using a granular model composed of mesoscale crushable round bars. The breakage band was found to form according to two types of stress paths and different stress states. Round rods as particles mainly broke in the vertically split mode and laterally crushed mode under axial loading. In contrast, round rods broke in a combined vertically split and locally crushed mode under the condition of a lateral-unloading stress path. McDowell and Bono [7] simulated the micromechanics of particle fracture by simply replacing breakage particles with new smaller particles while maintaining constant mass. The evolution of a fractal particle-size distribution apparently was triggered by the similarly sized particles in the vicinity of the fracture. Estay and Chiang [8] studied a discrete crack model for simulating rock comminution processes by applying the discrete-element 
computational method. Their model is useful for predicting a failure mechanism because the results agree well with those of other, similar studies. They classified fracture or crack patterns according to different types of loading: point-to-point, point-to-plane, and plane-to-plane loading.

Grady [9] considered local inertia and kinetic energy on a microscopic level for prediction of dynamic deformation and wave propagation in materials. Local-inertia forces, important for determining microstructural scale, were obtained by the model based on the dynamic-fracture and shear-band spacing in dynamic-shear localization. Based on theory inspired in part by Grady's model, Bažant and Caner [10] proposed the microplane model for constitutive laws of materials to determine the mesoscale particles that yielded by comminuting. In contrast to a number of continuum models proposed in the past that considered the fracture caused by the release of strain energy, their model is based on the release of local kinetic energy and yields minimum particle size. Rabczuk and Belyschko [11] simulated cracking as a result of large three-dimensional deformation by using a meshfree method for arbitrarily evolving cracks and found that experimental crack patterns and damage are accurately predictable. Caicedo et al. [12] proposed an analytical model to calculate the evolution of particle-size distribution due to crushing of granular materials. We have found their model to be useful for describing experimental results.

The performance of our rod-mill device is sufficiently satisfactory compared with conventional machines; however, the fragmentation mechanism in the jar is not clear. Thus, to help improve the performance of the device, we observed what happens in the jar and measured the magnitude of forces generated by the device. Also considering improvement of crushing events, Saeidi et al. [13] experimentally investigated the effects of strain rate applied to a single breakage event and found that the characteristics of primary breakage of a clod were nearly identical for devices using compression and impact mechanisms. To investigate the destruction process of clods, the fragmentation sequence was recorded by taking high-speed moving images, and the magnitudes of forces generated by our rod-mill device were measured. Initially, the surface of a clod was worn down and dust of the ground soil was suspended in the capsule of our rod-mill device. We found that instead of the rod's frequently colliding with clods, a clod abruptly fragmented into small pieces after a certain length of time had elapsed after starting the device. We interpreted this to mean that it is necessary to accumulate sufficient destructive energy to fragment the soil rather than to supply large energy impulses. In addition, we noted that occasional impacts of rods that we had put in the jar with the clods led to sudden soil fragmentation. These observations suggest ways to improve performance of our device and to make future changes in its design. In this study, we experimentally investigated the effects of compression and shear stresses on crushing a clod by using vibration and abrasion devices to make clear the sufficient forces for the crushing. We found that crushing occurred in our rod-mill device at lower stress levels than the critical forces of the amorphous yield point. The shearing forces 
caused by planetary rotation produced by the rods are more effective than the compressive forces in comminution by our rod-mill machine.

\section{Experimental Equipment and Methods}

\subsection{Rod Mill}

We developed a new type of rod mill (Japanese patent No. 5055524) (Figure 1) for use at a research institute. To obtain soil particles of median size of $<2$-mm diam. for analysis, we used the following operating procedure:

1) Put the sampled clods and two rods in a jar (Figure 2).

2) Put the jar on a turntable (Figure 2). As many as four jars may be set on the turntable. Noise arising from rods violently moving about in the jar(s) is suppressed by an outside cover, and rotation noise from the gears is quelled by the lid on the machine.

3) Soil particles that pass through the sieve fall cleanly into a collector cup, without the escape of soil dust.

4) Collected soil particles enter the analysis phase. A turning bed, tilted at a $20^{\circ}$ angle, causes the clods and rods in the jar to move randomly. Their movement is more complex than if motion were just in a horizontal plane because of the addition of rotational motion around the horizontal axis.

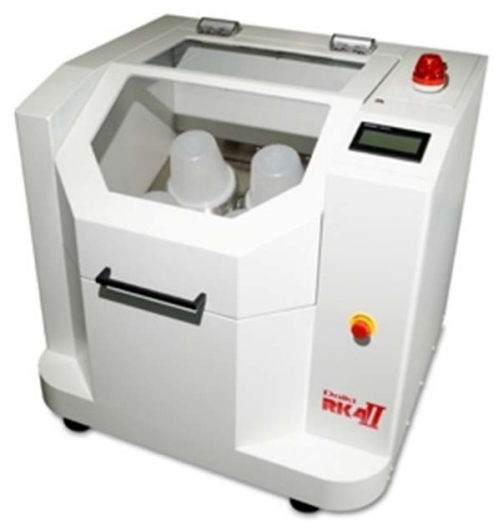

Figure 1. Rod mill (DIK-2610, Daiki Co.), which operates without release of soil dust into the surroundings and functions to transform the median size of soil particles to be $<2-$ mm diam.

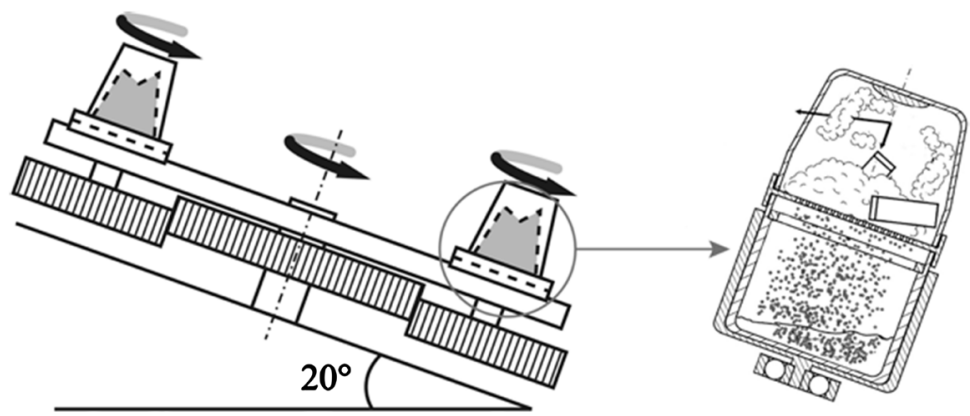

Figure 2. Schematic of turntable of rod-mill device (left) and enlarged view of jar (right). The rotational table is inclined to 20 degrees. 


\subsection{Impact and Wear Testing}

We tried to separate the powdering process by the compression and the wear processes. To be focusing on the compression, we made a vibrating container (Figure 3) and to use for determining various parameters. Its frequency of sinusoidal vibration is $8.13 \mathrm{~Hz}$, which relates to the driving revolution of the rod-mill device (488 rpm). Because its amplitude of vibration is $10 \mathrm{~mm}$, this machine could accelerate a clod to a speed of $0.51 \mathrm{~m} / \mathrm{s}$ if it moved at the same speed as that of the capsule, and the maximum acceleration was $26 \mathrm{~m} / \mathrm{s}^{2}$. Given a mass of a testing clod as $2.6 \times 10^{-3} \mathrm{~kg}$, the maximum compression due to impacting the ends of the capsule was $0.068 \mathrm{~N}$, the result of momentum changes with $180^{\circ}$ phase shifts. This is the same order of the compressive force given by our rod mill. This vibrating machine was expected just to be used to apply impact compression to clods.

Our original wear-testing machine, the abrasion-resistance tester BIK6556, is shown in Figure 4. The stroke of the cantilever on which a weight is put to change load is variable in the range $2-120 \mathrm{~mm}$. In our experiment, the cantilever

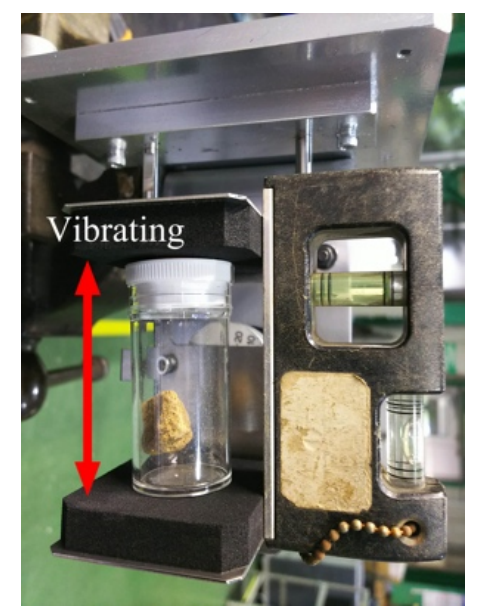

Figure 3. Vibrating container.
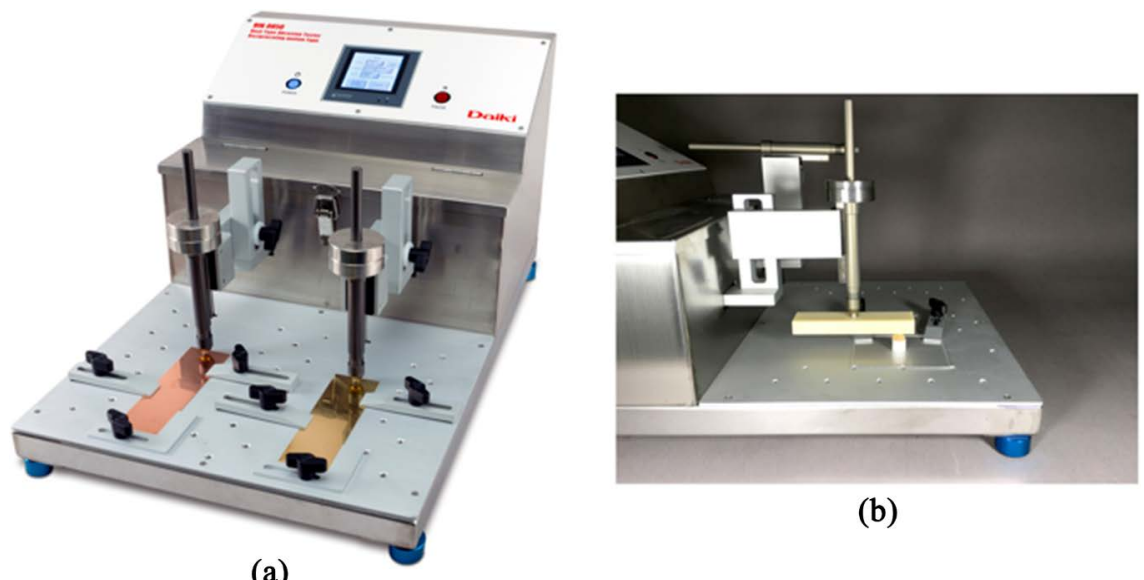

(b)

Figure 4. (a) Abrasion-resistance tester BIK6556; (b) Sliding arm and attached resin plate with weight. 
reciprocated sinusoidally, with an amplitude of $25 \mathrm{~mm}$. The frequency of the cantilever motion is changeable within the range $10-60 \mathrm{rpm}$. The details of specification are shown in Table 1 . We used a setup frequency of $60 \mathrm{rpm}$ and load weight of $14.7 \mathrm{~N}$ on the cantilever. The stress and change in height between the cantilever and base were measured by a stress sensor and a space sensor. The process of clod crushing was captured by a high-speed (240-fps) CCD camera.

\subsection{Soil Sample}

In our experiment, we used a soil sample from the Kanto district in Japan. Derived from volcanic ash, the sample contained ferric oxide (12.1\%) and clay $(25.0 \%-37.5 \%)$. Because results are influenced by a soil's water content, usually crushing tests are done on dry clods. Therefore, first, we dried the testing soil samples at $105^{\circ} \mathrm{C}$ for 5 days. To measure its water content after the initial drying, we used a Karl Fischer Moisture Titrator, which combines vaporization apparatus EV-6 and measuring apparatus AQV-7 (Hiranuma Co.). We found that the treated soil included $10.7 \mathrm{wt} . \%$ water.

The chemical composition of the soil (Table 2) was determined by using the wavelength-dispersive fluorescent X-ray analyzer ZSX101e (Rigakudenki Co.). The soil sample contains mainly silica (47.5\%), aluminum oxide (33.6\%), and ferric oxide (12.1\%).

We used the laser-diffraction particle-size analyzer SALD-3100 (Shimadzu Co.) to measure the size distribution of the soil particles after crushing.

\section{Results and Discussion}

\subsection{Crushing Clods in a Rotating Jar}

We recorded the clods-crushing process by using a high-speed CCD camera and an LED light, which were attached to the jar cover. Clods weighing $0.150 \mathrm{~kg}$ were stirred $2 \mathrm{~min}$. in the jar as it rotated by a planetary gear. When only clods were in the jar, most of the clods were still as intact as before stirring, with only a small amount of powder falling through the sieve (Figure 5(b)). Apparently, the complicated stirring only scraped away surficial soil powder from each of the clods.

Table 1. Specifications of wear-testing machine.

\begin{tabular}{cc}
\hline Characteristic & Specification \\
\hline Stroke & $2-120 \mathrm{~mm}(1-\mathrm{mm}$ precision $)$ \\
Frequency & $10-60$ per minute \\
Repeat count & $1-100,000,000$ times \\
User options & 15 cases \\
Power supply & AC $100-240 \mathrm{~V}, 50 / 60 \mathrm{~Hz}$ \\
Dimensions & W380 $\mathrm{mm} \times \mathrm{D} 590 \mathrm{~mm} \times \mathrm{H} 310 \mathrm{~mm}$ \\
Weight & $22 \mathrm{~kg}$
\end{tabular}


Table 2. Soil components.

\begin{tabular}{cc}
\hline Component & Amount (mass percent) \\
\hline $\mathrm{MgO}$ & 1.7277 \\
$\mathrm{Al}_{2} \mathrm{O}_{3}$ & 33.6425 \\
$\mathrm{SiO}_{2}$ & 47.5489 \\
$\mathrm{P}_{2} \mathrm{O}_{5}$ & 0.2339 \\
$\mathrm{SO}_{3}$ & 0.4039 \\
$\mathrm{Cl}$ & 0.8168 \\
$\mathrm{~K}_{2} \mathrm{O}$ & 1.3569 \\
$\mathrm{CaO}$ & 0.4612 \\
$\mathrm{TiO}_{2}$ & 1.3894 \\
$\mathrm{MnO}$ & 0.2673 \\
$\mathrm{Fe}_{2} \mathrm{O}_{3}$ & 12.0768 \\
$\mathrm{CuO}$ & 0.014 \\
$\mathrm{ZnO}$ & 0.0191 \\
$\mathrm{Br}$ & 0.0077 \\
$\mathrm{SrO}$ & 0.0083 \\
$\mathrm{ZrO}$ & 0.0257 \\
\hline
\end{tabular}

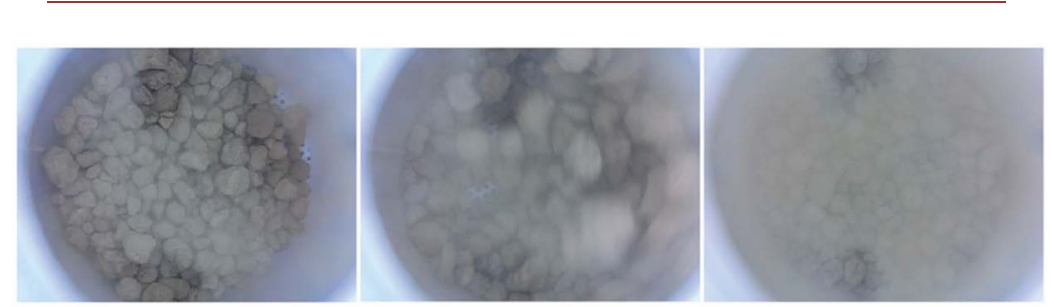

(a)

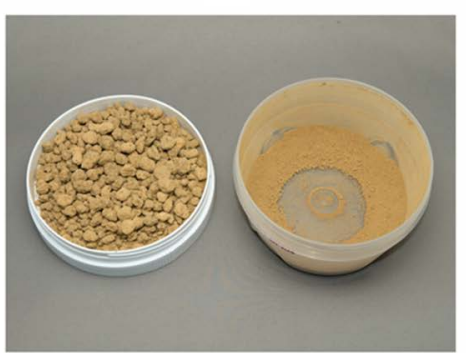

(b)

Figure 5. Case when only clods were in jar: (a) Process of stirring clods in jar; and (b) result after two minutes of stirring.

When clods and two rods are combined in the jar (Figure 6), the clods break into smaller particles $(<2-\mathrm{mm}$ diam) within two minutes of stirring. This means that the use of rods is important for crushing. Figure 7 shows the frequency distribution of soil-particle sizes after crushing as a bar chart. That $65 \%$ of the particles were reduced to $1-\mathrm{mm}$ diam shows that our rod mill's design requirements work well. Initially, soil dust due to abrasion was observed in the jar during the 


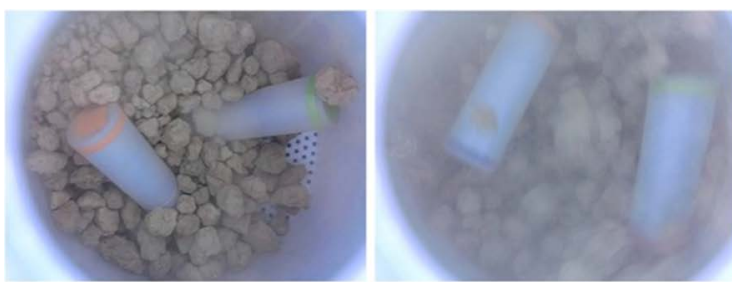

(a)

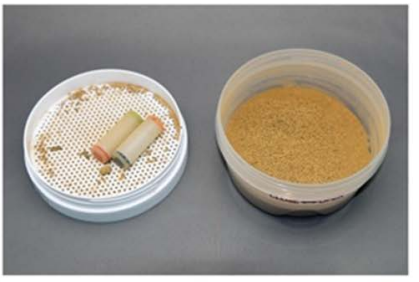

(b)

Figure 6. Case when clods and two rods were combined in jar: (a) Process of stirring; and (b) result after two minutes of stirring.

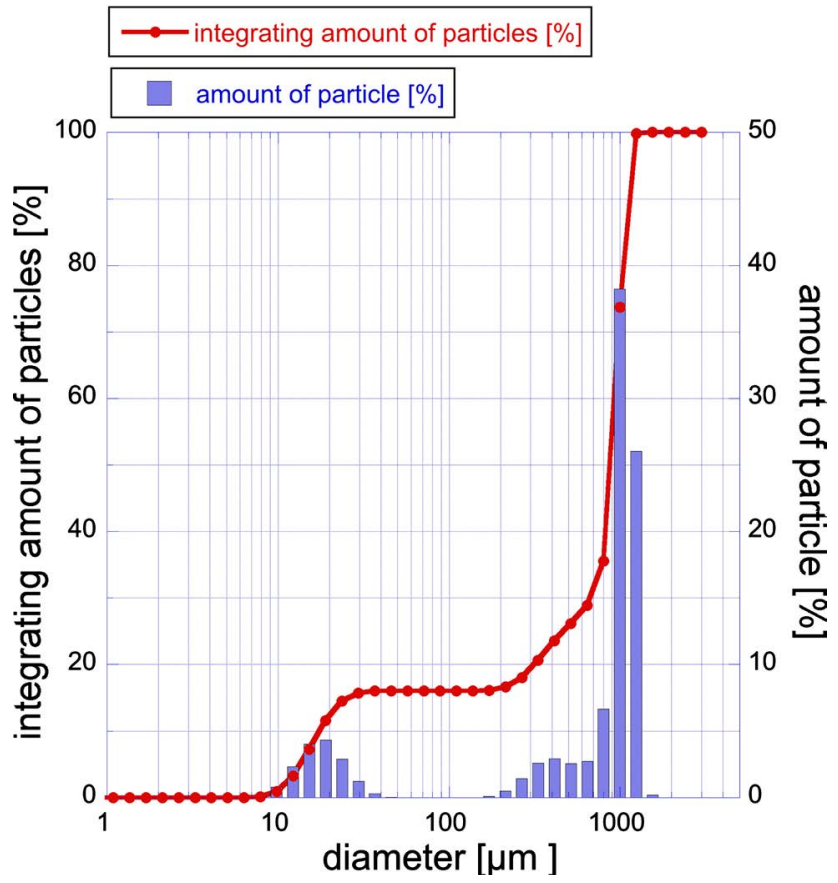

Figure 7. Frequency distribution of size of soil particles after crushing.

crushing process, as shown in the blurry photo in Figure 6(a). A cause of the dust could have been that surfaces were worn initially by shearing forces. As the crushing did not happen if there were no rods in use, apparently the rods but not the jar surface played an important role in the shearing action that produced the dust.

Because a rod mill normally needs many rods, we questioned why our preliminary experiments showed that the combination of two rods was best for crushing quickly in our rod mill. We have tried the change the number of rods in a jar for the crushing. The results by using two rods show the advantage to reduce the working time and to break into smaller particles $(<2-\mathrm{mm}$ diam). However, the mechanism of crushing using only two rods in the rotating jar remains unclear. This has been our motivation to carry out fundamental clods-crushing experiments as the impacting and the wearing processes. We sought to find out what kinds of strains cause crushing of clods in the rotating jar, whether or not the maximum strength exceeds the yield stress of the soil, and by what mechanism rods achieve quick crushing. The sections following 
show the results of our fundamental experiments to investigate these questions.

\subsection{Repeated Collisions of a Clod in an Oscillating Container}

To understand what is happening during repeated collisions of a clod with a wall, we observed the change of states of a clod in a vertical oscillating container (Figure 8).

Starting with an initial clod mass of $2.6 \times 10^{-3} \mathrm{~kg}$, we noted that the clod mass decreases logarithmically with the passage of time but that its mass did not change within 2 minutes (Figure 9). Moreover, even if two hours passed, crushing was not observed. The maximum impact force in the vertical oscillating container was $0.42 \mathrm{~N}$, according to the calculation of change of momentum of
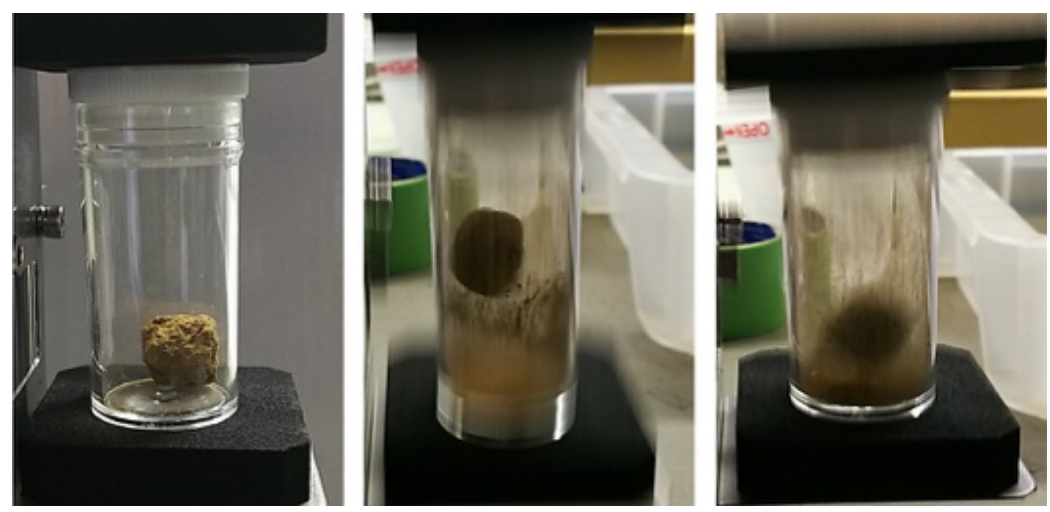

Figure 8. Repeated collisions during vertical oscillation.

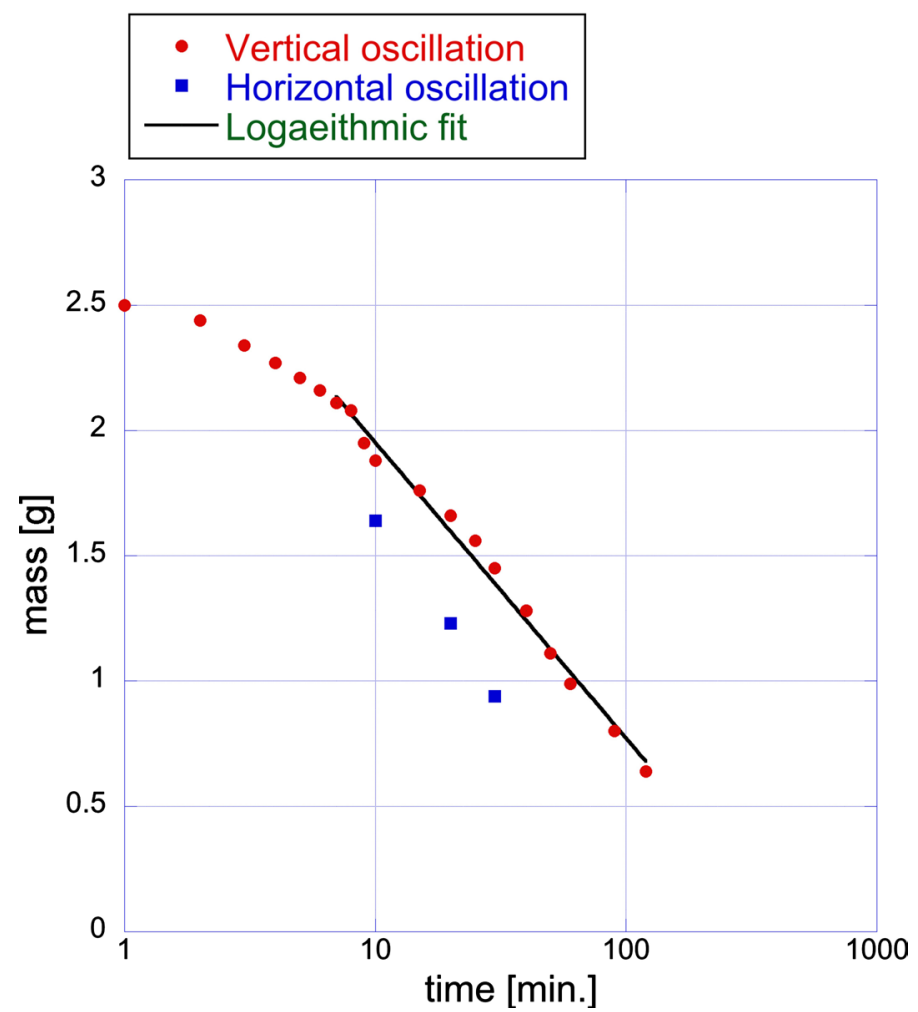

Figure 9. Change of mass of clod with time. 
the clod. In contrast, the maximum impact force in the horizontal oscillating container was $0.068 \mathrm{~N}$, as described previously. However, the yielding force of the tested soil is about $52 \mathrm{~N}$, based on the results of our tests using the universal material test equipment Instron 5566. Therefore, the impact force given by the oscillating container is $\sim 8 / 1000$ in the vertical case and $\sim 1 / 1000$ in the horizontal case smaller than the yielding force. From these results, it is clear that the clods never crush under this experimental condition. Given that the oscillating motion of the container simulated that of the rotating jar of our rod mill, this result shows that clods in the rotating jar do not get crushed.

Nakata et al. [14] and Saeidi et al. [13] extensively studied single-particle crushing by one-dimensional compression experiments as well as numerically. Such tests usually are used to examine crushing by static loading under very slow compression. Huang et al. [15], who studied the effects of strain rate on particle-size distribution, found that the compression stress to crush soil increases with increasing strain rate and thus that impact crushing requires higher stress than static compression does. A clod's yield stress is lower the larger its particle sizes and the higher the initial void ratio. The red clay of our soil sample consisted of mostly 1-mm-diam particles (Figure 7). Therefore, the void ratio is assumed to be large, because these particles are comparatively large. This may be one reason a clod could be crushed by the small force exerted by our oscillating container. According to Bažant and Caner's [10] proposed analysis of the effect of strain rate on particle size and given the experimental data obtained by Saeidi et al. [13], the particle sizes of broken fragments by impact compression are slightly smaller than those by static-loading compression. Thus, small particles, in the range 15 - $20 \mu \mathrm{m}$ (see Figure 7), are considered to be produced by impact compression.

We also considered whether clod strength might decrease as a result of the effect of fatigue [12] by repeated loading. However, the number of collisions in this experiment was several hundred, so an attempt to interpret the effect of fatigue on crushing times as short as two minutes is difficult at best, and crushing did not occur even after the passage of two hours in the oscillating container. This means that shearing stress rather than compression stress may have caused crushing. To check this, we also tested whether crushing could be due to the shearing stress, and the results are discussed in the following section.

\subsection{Observation of Clod Crushing Wearing Device}

As discussed in Section 3.1, crushing was not observed when only clods were in the rotating jar but occurred successfully when clods together with two rods were in the jar. From observation of the combined motions of clods and rods in the jar, the differences of their motions apparently caused abrasion between them. We simply simulated that interaction by using the abrasion-resistance tester BIK 6556. Figure 10 shows an example of test results as sequential photos. Time 0 shows the starting time of the cantilever to begin the reciprocating motion. At 


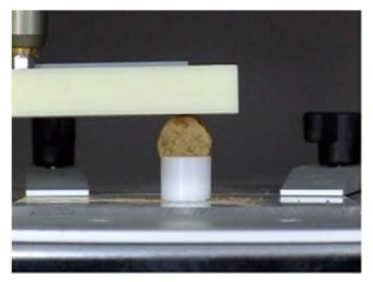

$0.0 \mathrm{~s}$.

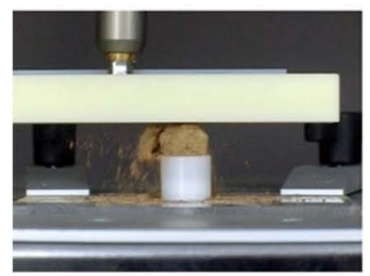

$37.8 \mathrm{~s}$.

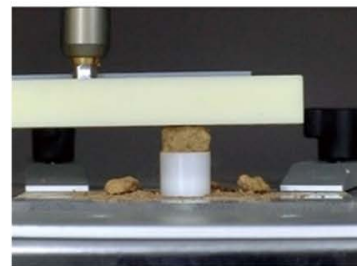

$38.5 \mathrm{~s}$.

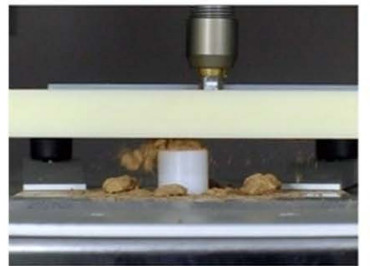

$40.6 \mathrm{~s}$.

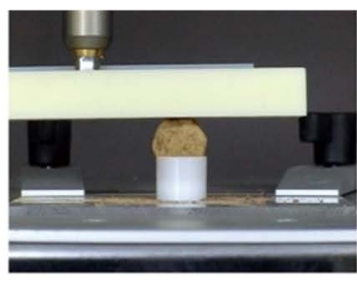

$10.0 \mathrm{~s}$.

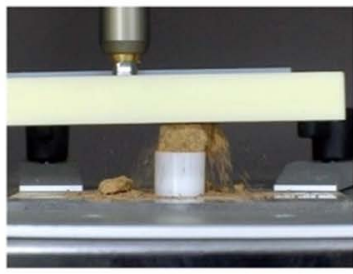

$38.1 \mathrm{~s}$.

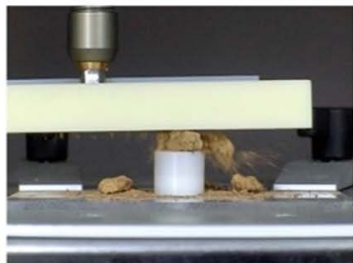

$40.1 \mathrm{~s}$.

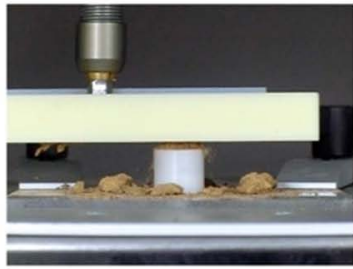

$41.1 \mathrm{~s}$.

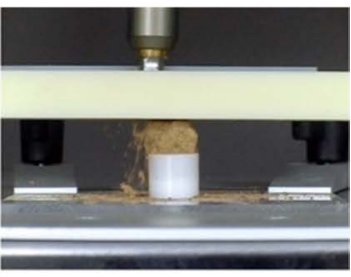

$37.7 \mathrm{~s}$.

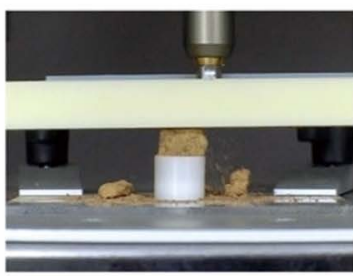

$38.3 \mathrm{~s}$.

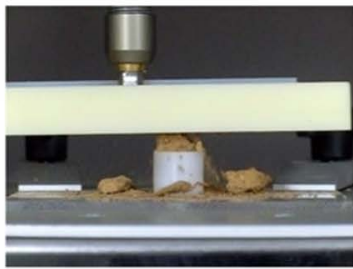

$40.3 \mathrm{~s}$.

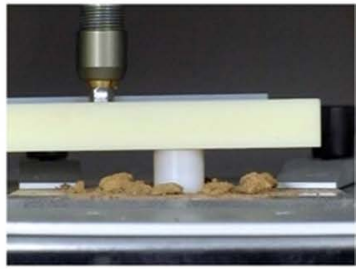

$45.0 \mathrm{~s}$.

Figure 10. Example of abrasion sequence.

first, the fine particles are ground from the surface of a clod. Small pieces of the clod begin to separate after 37.7 seconds. A typical large inclined crack due to shearing stress is seen in pictures of the clod at 37.8 and 38.5 seconds. Small spaces and/or small cracks between particles trigger large cracks under shear stress [11] [16]. The shearing force produced by the BIK 6556 device is $1.5 \mathrm{~N}$, much smaller than the compression force exerted by the Instron 5566. Therefore, the effect of rods is thought to be the shearing force due to rubbing clods.

The height of the cantilever measured from a surface at the base of the device through time did not change much until $37.7 \mathrm{~s}$ (Figure 11). Powder is scraped off the surface of a clod during the experiment. It likely takes time to accumulate shearing stress as potential energy inside the clod. Considering the potential energy [5] [10] of a spring system among particles from a microscopic point of view, the spacing between them, which relates to particle distribution as a soil structure [17], is an important parameter. Because material characteristics (i.e., porosity [12], void ratio [12] [18], and initial crack [5] [8] [11]), are not the same from one clod to the next, the timing of stress accumulation depends to a considerable extent on their differences. Once crushing begins, the time needed for a 


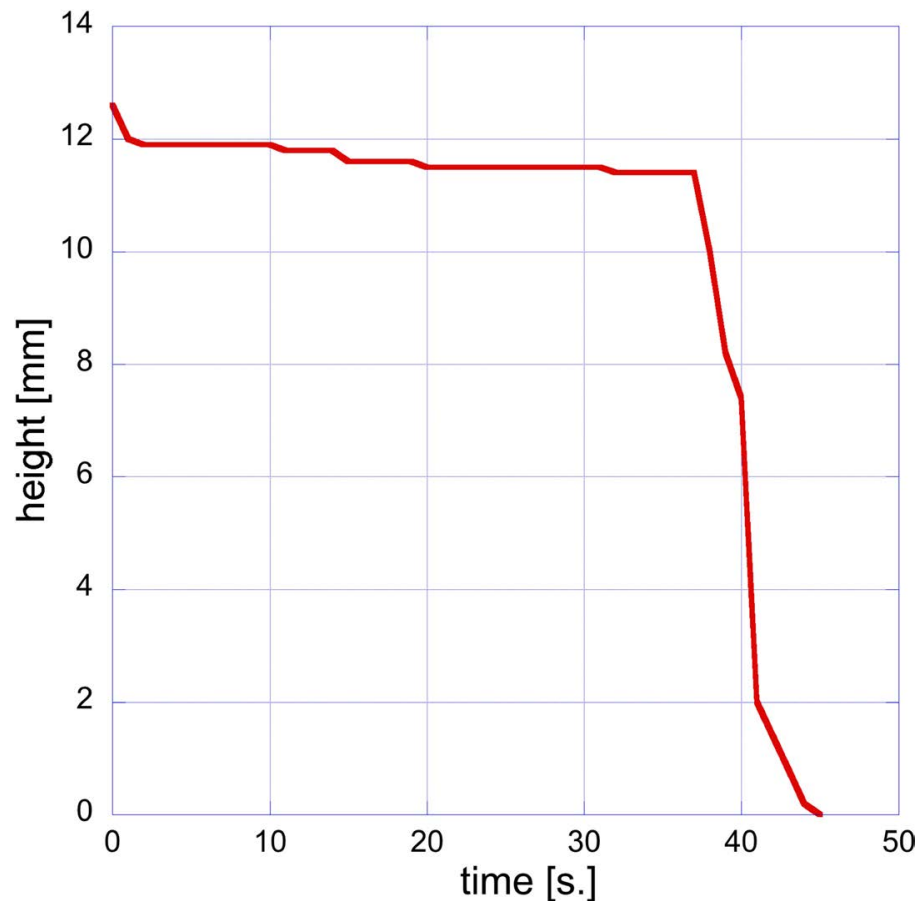

Figure 11. Change in cantilever height through time.

clod to break into small fragments ranges from the initial $7.3 \mathrm{~s}$ to as long as 37.7 s, when the crush appears to occur catastrophically (Figure 10), shown in the curve (Figure 11) as a rapid drop in cantilever height.

\section{Conclusion}

To make clear the crushing mechanism in a rotating jar of a newly developed rod-mill machine, we investigated crushing by means of fundamental experiments. Our questions concerned what kinds of strains cause the crushing of clods in the rotating jar, whether or not the maximum strength exceeds the yield stress of the soil, and what is the function of rods during quick crushing. We carried out compressive and shear stress tests using a vibrating container and shearing device to observe the crushing mechanism due to a single stress acting on a clod. The experimental crushing tests were recorded visually. Centrifugal forces produced by rotation of our machines' jar were found to be much smaller than the critical forces of the clods' amorphous yield points. Crushing did not happen if there were no rods with the clod in the jar but occurred in a short time if two rods were in the jar with the clod. Initially in the crushing process, soil dust due to abrasion was observed in the jar. This early-stage soil dust apparently arose because the clod's surface initially is worn by shearing forces caused by the rods. After the surface of a clod is scraped, it fragments into small particles catastrophically. The shearing forces produced by the rods are more effective than the compressive forces in comminution by our rod-mill machine. These results suggest that the crushing of clods needs to consider the sequence of adding the shearing and the compressive forces to develop the milling device. 


\section{Conflicts of Interest}

The authors declare no conflicts of interest regarding the publication of this paper.

\section{References}

[1] Powell, M.S. and Morrison, R.D. (2007) The Future of Comminution Modelling. International Journal of Mineral Processing, 84, 228-239. https://doi.org/10.1016/j.minpro.2006.08.003

[2] Vogel, L. and Peukert, W. (2003) Breakage Behaviour of Different Materials-Construction of a Master Curve for the Breakage Probability. Powder Technology, 129, 101-110. https://doi.org/10.1016/S0032-5910(02)00217-6

[3] Gay, S.L. (2004) A Liberation Model for Comminution Based on Probability Theory. Minerals Engineering, 17, 525-534.

https://doi.org/10.1016/j.mineng.2003.11.012

[4] Lobo-Guerrero, S. and Vallejo, L.E. (2005) Analysis of Crushing of Granular Material under Isotropic and Biaxial Stress Conditions. Soils and Foundations, 45, 79-87. https://doi.org/10.3208/sandf.45.4_79

[5] Tromans, D. (2008) Mineral Comminution: Energy Efficiency Considerations. Minerals Engineering, 21, 613-620. https://doi.org/10.1016/j.mineng.2007.12.003

[6] Liu, E. (2010) Breakage and Deformation Mechanisms of Crushable Granular Materials. Computers and Geotechnics, 37, 723-730.

https://doi.org/10.1016/j.compgeo.2010.04.009

[7] McDowell, G.R. and de Bono, J.P. (2013) On the Micro Mechanics of One-Dimensional Normal Compression. Géotechnique, 12, 41-54.

https://doi.org/10.1680/geot.12.P.041

[8] Estay, D.A. (2010) Discrete Crack Model for Simulating Rock Comminution Processes with Discrete Element Method. International Journal of Rock Mechanics and Mining Sciences, 60, 125-133. https://doi.org/10.1016/j.ijrmms.2012.12.041

[9] Grady, D.E. (1982) Local Inertial Effects in Dynamic Fragmentation. Journal of Applied Physics, 53, 322-325. https://doi.org/10.1063/1.329934

[10] Bažant, Z.P. and Caner, F.C. (2014) Impact Comminution of Solids Due to Local Kinetic Energy of High Shear Strain Rate: I. Continuum Theory and Turbulence Analogy. Journal of the Mechanics and Physics of Solids, 64, 223-235. https://doi.org/10.1016/j.jmps.2013.11.008

[11] Rabczuk, T. and Belytschko, T. (2007) A Three-Dimensional Large Deformation Meshfree Method for Arbitrary Evolving Cracks. Computer Methods in Applied Mechanics and Engineering, 196, 2777-2799. https://doi.org/10.1016/j.cma.2006.06.020

[12] Caicedo, B., Ocampo, M. and Vallejo, L. (2016) Modeling Comminution of Granular Materials Using a Linear Packing Model and Markovian Processes. Computers and Geotechnics, 80, 383-396. https://doi.org/10.1016/j.compgeo.2016.01.022

[13] Saeidi, F., Yahyaei, M., Powell, M. and Tavares, L.M. (2017) Investigating the Effect of Applied Strain Rate in a Single Breakage Event. Minerals Engineering, 100, 211-222. https://doi.org/10.1016/j.mineng.2016.09.010

[14] Nakata, Y., Kato, Y. and Murata, H. (2001) One-Dimensional Compression Behaviour of Uniformly Graded Sand Related to Single Particle Crushing Strength. Soils and Foundations, 41-42, 39-51. https://doi.org/10.3208/sandf.41.2_39 
[15] Huang, J.Y., Hu, S.S., Xu, S.L. and Luo, S.N. (2017) Fractal Crushing of Granular Materials under Confined Compression at Different Strain Rates. International Journal of Impact Engineering, 106, 259-265.

https://doi.org/10.1016/j.ijimpeng.2017.04.021

[16] Kamon, M. and Maekawa, K. (1992) Microscopic Observation of Shear Pale of Soils. Annuals of Disaster Prevention Research Institute, Kyoto University, 35-B2, 289-303. http://hdl.handle.net/2433/72407

[17] Rabot, E., Wiesmeier, M., Schlüter, S. and Vogel, H.-J. (2018) Soil Structure as an Indicator of Soil Functions: A Review. Geoderma, 314, 122-303.

https://doi.org/10.1016/j.geoderma.2017.11.009

[18] Nakata, Y., Hyodo, M., Hyde, A.F.L., Kato, Y. and Murata, H. (2001) Microscopic Particle Crushing of Sand Subjected to High Pressure One-Dimensional Compression. Soils and Foundations, 41-1, 69-82. https://doi.org/10.3208/sandf.41.69 